\title{
An Exploration of Patients' Experiences of Mechanical Ventilation
}

\author{
M. S. P. Marasinghe, W. I. T. Fonseka, P. C. Wanishri, N. K. \\ S. M. Nissanka*, B. S. S. De Silva \\ Department of Nursing, The Open University of Sri Lanka
}

\begin{abstract}
Mechanical ventilation is a part of the most frequently used technological treatments in Intensive Care Units (ICU) which facilitates the gas exchange to the lung in impaired breathing situations. However, it is a stressful and frustrating experience for patients. Therefore, the aim of this study is to explore the experiences of mechanical ventilation of patients admitted to ICUs in the National Hospital of Sri Lanka, the Teaching Hospital in Peradeniya and the District General Hospital in Nuwara-Eliya.
\end{abstract}

The purposive sample of 15 mechanically ventilated patients was recruited for this phenomenological study to collect the data during one month by using semi structured interviews. Data was analyzed by thematic analysis method. A total of 11 sub themes and three main themes were identified. All these themes are reflections of intra personal, extra personal and interpersonal experiences of the patients. The feeling of inner suffering such as pain, dependency, fear and anxiety, thirst, noise level, cold environment and nightmares were identified while on mechanical ventilation. Further, the body intolerances such as feelings of congested secretions, experiences of suctioning, inspiration by ambu and chest physiotherapy were reported. Patients further noted that an inability to speak, diverse way of communication and inability to express feelings as being more stressful and frustrating. Mechanically ventilated patients tolerate many stressors during mechanical ventilation at moderate to high levels of distress. Hence exploring experiences of mechanical ventilated patients can be used to provide them with better care that will reduce their stressors when they are on a ventilator.

Keywords; Patients' experiences, mechanical ventilation, ventilator

\footnotetext{
${ }^{*}$ Correspondence should be addressed to Ms. N. K. S. M. Nissanka, Department of Nursing, Faculty of Health Sciences, The Open University of Sri Lanka, Nawala, Sri Lanka.

(Email: samani.nissankasandhya@gmail.com)
} 


\section{Introduction}

Mechanical ventilation is a supportive therapy which facilitates the gas exchange of the lung with the use of mechanical apparatus when there are impaired breathing situations of the patients. It is the most widely used life supportive technique in Intensive Care Units (ICUs) in hospitals all over the world (Brochard, 2003). Despite the dramatic development in technology of the mechanical ventilator, it is still described as a stressful and frustrating experience for patients (Granja et al., 2005). Since the early days, the use of the mechanical ventilator named as the iron lung machine, to the modernized ventilator, studies have been conducted on patients' experiences of mechanical ventilation. Many of them highlighted that experiences of mechanically ventilated patients are very stressful. While on the mechanical ventilator most patients were conscious, but paralyzed with medicine. Therefore, mechanically ventilated patients undergo various experiences, including pain, lack of peace, fear, anxiety, lack of sleep, feeling tense, and the inability to speak or communicate, which are unique to each (Arabi \& Tavakol, 2009; Guttormson, 2011; Rotondi et al., 2002).

According to the literature, there had been many studies on intrapersonal, extra-personal, and interpersonal experiences of patients in ICU. A phenomenological study conducted by Arabi and Tavakol (2009) in Iran, found some of intra personal experiences such as coping with the present condition, changes in self-image, loneliness, pain and lack of peace, nightmares, unfamiliar environment and changes in physiological needs. The authors concluded that the mechanically ventilated patients' experiences were unpleasant (Tavakol, 2009).

A prospective cohort study of Rotondi et al, (2002) revealed that two third of the sample were strongly associated with experience of pain, fear, anxiety, and lack of sleep and feeling tense. A phenomenological study conducted by Lykkegaard, and Delmar (2013), unveiled that dependency had been a difficult experience related to mechanical ventilation. Moreover, Johansson, Bergbom and Lindahl (2012), indicated the need to reduce disturbing and unexpected sound and noise around the critically ill. Furthermore, Granja et al., (2005) conducted a study in ten Portuguese ICUs. The result revealed that $64 \%$ of patients experienced pain and $51 \%$ of patients reported bad experience of dreams and nightmares.

Many studies done worldwide on mechanical ventilated patients highlighted that their discomfort and extra-personal experience are 
more extensive. The study of Arabi and Tavakol (2009) indicated that their extra personal experience includes difficulties with suctioning, change in position, chest physiotherapy, personal health, and change in sleep pattern, weaning, inspiration by ambu, and vital dependency to intra venous medication as important. Studies from both developing countries and developed countries stated extrapersonal experiences as stressful. Granja, et al., (2005) found that $81 \%$ of patients reported that tracheal tube aspiration is more stressful and $75 \%$ of patients reported difficulties about the nasal tube.

Interpersonal experiences include communication deprivation, communication by writing, one-way verbal communication and touch which the patients experienced toward physicians, nurses and their accompanying persons (Arabi \& Tavakol, 2009; Khalaila et al; 2011; Patak, et al., 2005).

Communicating with others is a main difficulty with ventilated patients and a cross sectional correlation study conducted by Khalaila et al, (2011) found that fear and anger were presented in relation to difficulty in communication. The authors have concluded that patients treated with mechanical ventilation experienced a moderate to extreme level of psycho emotional distress because they cannot speak and communicate their needs. Further, Patak, et al., (2005) conducted a study and found that $62 \%$ of patients reported a high level of frustration in communicating their needs while being mechanically ventilated. Rotondi et al. (2002) and Tosun et al. (2009) reported the inability to communicate and the difficulty to be understood had been described as uncomfortable stressful experiences of ventilated patients.

The literature provided important insight into the patients' experiences of mechanical ventilation in relation to most of the countries. However, in the Sri Lankan context, literature related to patients' experiences of mechanical ventilation has not been identified. As Sri Lanka is a developing country with limited resources and specific cultural groups, their experiences of mechanical ventilation may be significant. Therefore, it is of paramount importance to explore the patients' experiences on this phenomenon and how they perceive and discuss their experiences related to mechanical ventilation in relation to the Sri Lankan context. 


\section{Methodology}

A descriptive phenomenological method exploratory descriptive was utilized in this study to explore the patients' lived experiences of mechanical ventilation. Since this qualitative approach is important to understand how people make sense of their experiences (Merriam, 2009), it was used as a powerful tool to understand subjective experiences (Hancock et al., 1998) of mechanically ventilated patients and gaining their insights (Lester, 2007). It is also important to recognize how people perceive and talk about their experiences (Marriam, 2009). Since the aim of this research is to explore the patients' experiences of mechanical ventilation, a qualitative research approach rather than a quantitative research method has been selected to explore the meaning, actions and interpretations of the patients' experiences of mechanical ventilation in relation to the Sri Lankan context.

\section{Study Settings and Participants}

The study was carried out in ICUs of three hospitals, namely the National Hospital of Sri Lanka, Teaching Hospital in Peradeniya and District General Hospital in Nuwaraeliya. These units have a nurse to patient ratio of one to one and all units use modern ventilators such as Centiva, Bennett 760, Bennett 840 and Newport. The purposive sample of 15 mechanically ventilated patients was recruited to collect the data during a one-month period which included eight females and seven male participants. All the participants were above 18 years and below 65 years old, who were mechanically ventilated patients for a minimum of 24 hours. Their ability to orient a person, place, time and the ability to speak Sinhala, Tamil or English languages were considered. Willingness to discuss feelings; competency and ability to sign an informed consent were also considered in this study as they were able to share their experiences related to mechanical ventilation. Any patient who had a tracheostomy or who was hemo-dynamically unstable at the time of the interview was excluded from the study.

\section{Ethical Consideration}

Ethical approval for the study was granted by the Ethical Review Committee of the National Hospital of Sri Lanka and Ethics Review Committee of the Faculty of Medicine at the University of Peradeniya and administrative clearance was also obtained from the relevant authorities. The patients were informed that their participation was completely voluntary and the ability to withdraw from their 
participation at any time without any consequences was left open. All participants were kept fully informed of the purposes, benefits, potential risks of the study before taking their informed consent.

\section{Data Collection}

Data was collected through face to face interviews conducted by coauthors based on a pre- formulated topic guide. Rice and Ezzy (1999) pointed out that a guided theme list or inventory of topics helps to cover all relevant issues that are required for investigating. On the other hand, this theme list did not have direct questions but it acted as a reminder regarding the topics that needed to be considered while interviewing. Supplementary questions such as "What; How; and Can you....." were added in order to encourage participants to describe their experiences in depth (Burns \& Grove, 2005). Fifteen participants were interviewed in their mother tongue individually. Every interview lasted for 40 to 50 minutes on average and was recorded on audio tapes with the prior permissions of the participants.

\section{Data Analysis}

The interviews were recorded on audio files, transcribed to verbatim, and de-contextualized to a text for analysis. Data analysis was made according to the method of qualitative thematic analysis described by Hycner, (1985). For this, several steps of Braun and Clarke (2006) have been followed such as being familiar with the data, extracting keywords, generate initial codes, clustering them to units of same meaning searching for themes, reviewing themes, defining and naming themes and producing the report. To maintain trustworthiness of the study data, the four steps credibility, transferability, dependability and conformability of the evaluative criteria model highlighted by Guba and Lincoln (1985) were utilized.

\section{Findings}

In the process of analysis, through the participants' experiences, three major themes were identified as "feeling of inner suffering", "body intolerance", and "disrupted interactions" from overall generated eleven sub themes. It was presented as a model which illustrates the patients' experiences of mechanical ventilation (Figure1). 


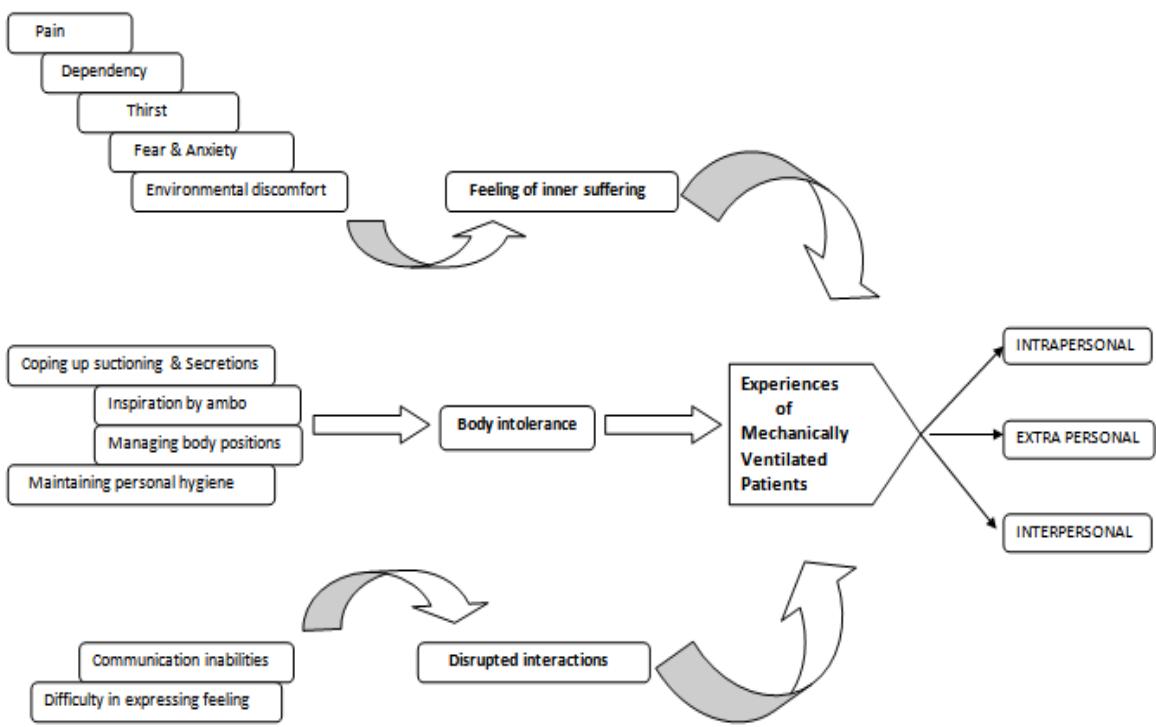

Figure 1. Mechanically ventilated patients' experiences and its influences upon them

\section{Feeling of Inner Suffering}

Even the main purpose of utilizing therapeutic support of the mechanical ventilator is to ensure the survival of the patient from life threatening conditions, while on the ventilator the majority of the patients are conscious, so that they can hear, feel everything which they are facing, except an inability to express their feelings and emotions. According to the participants, they had experiences of pain during mechanical ventilation and some had a sore throat due to the inserted endotracheal tube into the airway. Back pain was also a common discomfort due to the inability of moving their body for a longer period. Participant I highlighted that as;

It was pricking like a mass of iron strings. When the tube was removed, I sort of regained life. When turning to this side, it pricks. When on supine position, it is ok. I was unable to turn, it was unbearable. The back was irritating. I just obeyed the instructions to turn. I continued to turn as instructed, even though it pricked (Interview 09, participant I).

While on the mechanical ventilator, most patients are kept physically paralyzed so that it is limiting their activities of daily 
living. Further, it was highlighted that they cannot do activities without any other persons' support.

There was a back pain. Do you remember Miss, I asked you to help me with a pillow at the back. A severe pain came; I couldn't turn (Interview 06, participant F).

It is a universal truth that patients, who undergo unfamiliar therapy, commonly confront the feelings of fear and anxiety. This was also relevant to mechanically ventilated patients and they also encountered fear and anxiety as a major difficulty. This escalates with the lack of ability to express their feelings and emotions. Such feelings related to their fear and anxiety were expressed as follows;

I am waiting to see the face of the little one. I saw the elder daughter. I want to see the younger daughter too. How many days were they without me? I remembered all my children. I was afraid and disappointed. When the tube was taken away it was comfortable and I was happy (Interview 09, participant I).

While on the mechanical ventilator, it is difficult to take food and drink since the apparatus invades the whole mouth cavity of the patient. With this circumstance mechanically ventilated patients mainly endure the feeling of thirst as they do not have the ability to drink water while connected to the mechanical ventilator. They expressed this feeling of thirst as a major problem.

Thirst was there, I had an unquenchable thirst. I wanted to drink a pot of cold water. I felt like drinking cold water first. Lips were dry and when they wet my lips, it was so comforting (Interview 04, participant D).

The environment of an ICU where patients are kept mechanically ventilated is an unruffled place with less human interactions. However, due to the devices that are used to maintain lives of critically ill patients, it is surrounded with electronic noises most of the time all over the day. This is an ear -splitting situation for the patients who are conscious but kept on a bed alone without interaction with their relatives. Therefore, almost all participants described that the noise in the ICU as a bad experience and that they cannot sleep properly. Nightmares were common among some patients. Nevertheless, they highlighted that those sounds of alarms negatively affected their comfort. Participants also commented on the cold environment as unbearable. 
The alarm was bit irritable. It was intolerable at times. The AC was also unbearable. I have phlegm, that's why I think (Interview 04, participant D). I couldn't sleep from the day I came. If I sleep, I feel as if the tube is going in; going in and getting stuck inside. I couldn't sleep troubled by that fear (Interview 09, participant I).

Patients expressed their feelings about the cold environment. All ICU are generally air conditioned. However most of the time patients cannot tolerate the cold as they are always exposed to cold temperature continuously. One of the patient highlighted that he had secretions due to the air conditioned environment.

The air condition was unbearable. I felt very severe cold but I cannot communicate and feeling very sad. I think I have phlegm, because of this severe cold. (Interview 07, participant G).

All these common endeavors disclose the major concept or the theme of "feeling of inner suffering" and this reveals the participants intrapersonal suffering while on the mechanical ventilator.

\section{Body Intolerance}

Under the mechanical ventilator support, patients cannot spit out secretions and saliva and it is congesting within their air way and the mouth cavity. This has to be removed with the help of others. Some participants expressed that the feelings of congested secretions and experience of suctioning was painful and irritating whereas some had positive feeling on inspiration by ambo apparatus and chest physiotherapy.

The tube is painful. I felt, I had committed grave sins. I was almost dying. I thought, it was ok to die. When phlegm was removed, I felt a piece was going in. I questioned the existence of God. If they gave me air, it was ok. I felt like throwing the tube away (Interview 09, participant I).

I felt unable to breath, but when phlegm was removed, it was comfortable (Interview 08, participant $H$ ).

When Phlegm came out, that pressing on the chest was ok (Interview 06, participant $F$ ).

With the restricted activities, mechanically ventilated patients have to depend on others, especially on the nurses who are providing care for them. When the caring nurse is away from the patient they have to wait to change their position, and to fulfill essential needs like 
maintaining personal hygiene. This was accepted by the participants as a difficult for them.

Alas! I was unable to turn; I needed another person's help to turn. It was difficult move my body alone (Interview 02, participant B).

These incidents emphasized the extra personal experiences as their "body intolerance" happened due to the external environment. It was revealed that the external environment of the patient also influenced the mechanically ventilated patients.

\section{Disrupted Interactions}

While in the ventilator, patients cannot also talk and communicate with others due to the inserted mouth piece which helps them to breathe in and out. Even though this is essential for their life saving, all participants reported communication difficulties as moderate to extremely stressful. Participants were worried about their inability to speak, not being_understood and reported that they communicated with others by using hands.

By hitting the bar of the bed, I tried to communicate as I couldn't talk with these machines. Most of the time nurses cannot understand what I want to tell. When feel the barrier to communicate, it was severe stress (Interview 01 , participant A).

Participants also worried about the inability to express their feelings. They highlighted that it was a big problem and a negative experience related to mechanical ventilation.

I couldn't communicate; I just enjoyed looking at the faces of my loved ones. It was a very sad situation (Interview 07, participant D).

Likely, through the analysis of participants' feelings, it can be seen that the patients who were in a mechanical ventilator encountered a very unpleasant experience.

Findings of the present study reveal that the patients had different experiences of mechanical ventilation during their ventilated period. Most of them had experienced stress and suffering due to various reasons. Findings shows patient's intrapersonal experiences like pain, dependency, thirst, fear and anxiety as the most common experiences of ventilated patients. Further, noise level, cold environment and nightmares were other unpleasant experiences of mechanically ventilated patients. Secretions and suction, inspiration 
by ambu and chest physiotherapy were extra personal experiences most of the mechanically ventilated patients faced. Inability to speak, way of communicate and express feelings was an important interpersonal experience of mechanically ventilated patients.

\section{Discussion}

The findings of the present study identified that the patients had many experiences of mechanical ventilation during their ventilated period. In the process of analysis, three major themes were identified as feeling of inner suffering, body intolerance, and disrupted interactions from overall generated eleven sub themes.

Participants expressed that experiences related to mechanical ventilation negatively affected their comfort during mechanical ventilation. The study revealed that the participants had experiences of pain and sore throat related to the endotracheal tube and they pointed out back pain due to the inability to move their body. Both Sri Lankan and some Iranian patients complained of pain in throat and general pain (Arabi \& Tavakol, 2009). It may be due to the lack of changing position (Tosun et al., 2009). Dependency is reported as the most important source of stress in mechanical ventilation in this study as well as other studies (Lykkegaard \& Delmar, 2013; Tosun et al., 2009). It may be due to the patients' inability to convey their real feelings with an endotracheal tube and their lack of experience in nursing care management.

Moreover, participants expressed that the fear and anxiety were other stressful factors during mechanical ventilation. Similar results were found in the studies of Chlan and Savik (2011), Eng, Hassan, Saidi and Zulkfli (2008), and Patak, et al. (2004). It could be due to the fact that nurses and other health care workers neglect the patients' communication efforts (Patak, et al., 2004). In the study, the patients expressed their feelings about noise level and cold environment in the ICU as being more stressful, same as in Sweden (Johansson, Bergbom \& Lindahl, 2012). It might be due to the unfamiliar environment. Moreover, nightmares were highlighted as the most discomforting factor not only in Sri Lanka but also in Iran (Arabi \& Tavakol, 2009). It might be due to the fear of patients and not receiving enough information about their conditions by health care workers.

The study revealed that the experiences occurred due to the functions carried out by others or extra personally in relation to mechanical ventilation such as feelings of congested secretions, 
experiences of suctioning, inspiration by ambu and chest physiotherapy. Participants reported that such experiences were both positive and negative. In the study of Arabi and Tavakol (2009) that suctioning was difficult and stressful for the ventilated patients. Participants expressed that feelings of secretions and experience of suctioning were painful and irritating as reported both in Sri Lanka and in Netherlands (Leur, Zwaveling, Loef \& Schans, 2003; Tosun et al., 2009). Furthermore, participants had both positive and negative experiences about the inspiration by ambu and chest physiotherapy same as in Iran (Arabi \& Tavakol, 2009). They disclosed that the procedure was helpful and provided relief in the sense that it made their breathing easier after the secretions had been removed. While others expressed that the procedure of removing secretions produced pain and discomfort and therefore, they would rather not have it (Arabi \& Tavakol, 2009; Rotondi et al., 2002). This may be due to the air hunger and fear of the participants (Rotondi et al., 2002).

The study has found the communication barrier as a major problem for mechanically ventilated patients. Participants further noted the inability to speak, diverse ways of communication and inability to express feelings as being more stressful and frustrating. Participants highlighted the inability to speak and not being understood as stressful or difficult same as in Portugal (Granja et al., 2005). It might have happened due to health care workers being sometimes too busy and do not spend sufficient time attempting to understand patients' modes of communication (Patak, et al., 2004).

When considering the overall present study findings, participants had stressful and frustrating intra personal, extra personal and interpersonal experiences during mechanical ventilation. Participants expressed unpleasant and uncomfortable feelings while receiving mechanical ventilation.

\section{Conclusions}

The findings of this study focused to determine the experiences of patients on mechanical ventilation in ICUs. It has shown that they were associated with negative experiences with mechanical ventilation. Pain, dependency, fear and anxiety, thirst, noise level, cold environment and fear from sleep were described as uncomfortable and stressful intrapersonal experiences which patients suffered during mechanical ventilation. Furthermore, participants showed feeling of clogged secretion and difficulties with 
airway suction, inspiration by ambu, and chest physiotherapy as moderately discomforting. Participants expressed moderate to high levels of distress in trying to communicate their needs during mechanical ventilation. Understanding the real lived experiences of the patients leads to expand the knowledge of the health care workers, especially nurses and it will help to minimize patients' unpleasant experiences while they are on a ventilator.

\section{Acknowledgements}

We would like to express our deepest appreciation for all those who participated in this study including the participants, researchers and the supervisors. A special gratitude goes to the Ethical Review Board of the National Hospital of Sri Lanka and the Ethics Review Committee at the Faculty of Medicine at the University of Peradeniya.

\section{References}

Arabi, A., \& Tavakol, K. (2009). Patient's experiences of mechanical ventilation. Iranian Journal of Nursing and Midwifery Research, 14(2).

Boyce, C., \& Neale, P. (2006). Conducting in-depth interviews: A guide for designing and conducting in-depth interviews for evaluation input (pp. 3-7). Watertown, MA: Pathfinder International.

Brochard, L. (2003). Mechanical ventilation: invasive versus noninvasive. European Respiratory Journal, 22 (47 suppl), 31s-37s.

Braun, V. \& Clarke, V. (2006). Using thematic analysis in psychology. Qualitative Research in Psychology. 3: 77-101

Burns, N. \& Grove, S.K. (2005). The practice of nursing research: conduct, critique, and utilization.(5 ${ }^{\text {th }}$ ed.). St Louis: Elsevier Saunders.

Chlan, L., \& Savik, K. (2011). Patterns of anxiety in critically ill patients receiving mechanical ventilatory support. Nursing research, 60(3 Suppl), S50. 
Ho, S. E., Hassan, H., Saidi, S., \& Zulkfli, S. (2008). Recollections Expressed by Mechanically Ventilated Patients of Intensive Care Unit (ICU), Hospital Universiti Kebangsaan Malaysia (HUKM). Medicine \& Health, 3(1), 46-53.

Granja, C., Lopes, A., Moreira, S., Dias, C., Costa-Pereira, A., \& Carneiro, A. (2005). Patients' recollections of experiences in the intensive care unit may affect their quality of life. Critical Care, 9(2), R96.

Guba, E. G. (1981). Criteria for assessing the trustworthiness of naturalistic inquiries. ECTJ, 29(2), 75-91.

Guttormson, J. L. (2011). Patients' recall and evaluation of Mechanical Ventilation: Impact of Sedation (Doctoral dissertation, University of Minnesota).

Hancock, B., Ockleford, E., \& Windridge, K. (1998). An introduction to qualitative research. Nottingham: Trent focus group.

Hycner, R. H. (1985). Some guidelines for the phenomenological analysis of interview data. Human studies, 8(3), 279-303.

Johansson, L., Bergbom, I., \& Lindahl, B. (2012). Meanings of being critically ill in a sound-intensive ICU patient room-A phenomenological hermeneutical study. The open nursing journal, 6, 108

Khalaila, R., Zbidat, W., Anwar, K., Bayya, A., Linton, D. M., \& Sviri, S. (2011). Communication difficulties and psychoemotional distress in patients receiving mechanical ventilation. American Journal of Critical Care, 20(6), 470-479.

Lester, S. (2007). An Introduction to phenomenological research. Retrieved from http://www.sld.demon.co.uk/resmethy.pdf

Van de Leur, J. P., Zwaveling, J. H., Loef, B. G., \& Van der Schans, C. P. (2003). Patient recollection of airway suctioning in the ICU: routine versus a minimally invasive procedure. Intensive care medicine, 29(3), 433-436.

Lincoln,Y. S., \& Guba, E. G. (1985). Naturalistic inquiry. Beverly Hills, Calif: Sage. 
Lykkegaard, K., \& Delmar, C. (2013). A threat to the understanding of oneself Intensive care patients' experiences of dependency. Int. J Qualitative Stud Health Well-being, 2013; 8: 20934.

Merriam, S. (2009). Qualitative research: A guide to design and implementation. San Francisco, CA: Jossey-Bass.

Patak, L., Gawlinski, A., Fung, N. I., Doering, L., \& Berg, J. (2004). Patients' reports of health care practitioner interventions that are related to communication during mechanical ventilation. Heart \& Lung: The Journal of Acute and Critical Care, 33(5), 308-320.

Rice, L., \& Ezzy, D. (1999). Qualitative research methods: A health focus. South Melbourne: Oxford Press.

Rotondi, A. J., Chelluri, L., Sirio, C., Mendelsohn, A., Schulz, R., Belle, S., \& Pinsky, M. R. (2002). Patients' recollections of stressful experiences while receiving prolonged mechanical ventilation in an intensive care unit*. Critical care medicine, 30(4), 746-752.

Tosun, N., Ayla, Y. A. V. A., Ünver, V., Akbayrak, N., \& Hatipoğlu, S. (2009). Experience of Patients on Prolonged Mechanical Ventilation: A Phenomenological Study. Turkiye Klinikleri Journal of Medical Sciences, 29(3), 648-658.

Received: 20-5-2015 Revised: 29-9-2015 Accepted: 06-10-2015 